\title{
Hydrotherapy in Advanced Heart Failure: the Cardio-HKT Pilot Study
}

\section{L'idroterapia nello scompenso cardiaco: lo Studio Pilota Cardio-HKT}

\author{
Annamaria Municinó, Annamaria Nicolino, Manlio Milanese ${ }^{1}$, \\ Edoardo Gronda², Bruno Andreuzzi22, Fabrizio Oliva ${ }^{3}$, Francesco Chiarella, \\ on behalf of the Cardio-HKT Study Group
}

\begin{abstract}
Hydrotherapy in Advanced Heart Failure: the Cardio-HKT Pilot Study. A. Municinó, A. Nicolino, M. Milanese, E. Gronda, B. Andreuzzi, F. Oliva, F. Chiarella, on behalf of the Cardio-HKT Study Group.

Background: In-water exercise, hydrotherapy, may offer an attractive alternative to conventional training in markedly compromised patients with advanced HF. This Pilot Study evaluates the safety and efficacy of Cardio-Hydrokinesitherapy (Cardio-HKT) in patients with advanced HF on optimal medical therapy. Cardio-HKT is a novel rehabilitation program that includes training sessions in warm water $\left(31^{\circ} \mathrm{C}\right)$, integrated by educational and psycho-behavioural sessions to promote healthy life style modifications.

Methods: We studied 18 adult patients with advanced HF, LVEF $<35 \%$, NYHA functional class $>$ II and peak oxygen uptake (peak VO2) $<18 \mathrm{ml} / \mathrm{kg} / \mathrm{min}$. Cardio-HKT consisted of a 3 weeks daily in-water training, combined to educational and psycho-behavioural sessions. Patients under-
\end{abstract}

went a six-minute-walking-test (6mWT), a cardiopulmonary exercise test at baseline and after 3 weeks of CardioHKT. Quality of life was assessed with the Minnesota Living with Heart Failure Questionnaire (MLHF).

Results: All patients completed the Cardio-HKT rehabilitation program without complications. The $6 \mathrm{mWT}$ improved from $453 \pm 172 \mathrm{~m}$ to $571 \pm 120 \mathrm{~m}(\mathrm{p}<0.01)$, peak VO2 from $13.0 \pm 3.1$ to $14.5 \pm 2.9 \mathrm{ml} / \mathrm{kg} / \mathrm{min}(\mathrm{p}=0.03)$, whereas $\mathrm{VE} /$ CO2 slope declined from $37 \pm 10$ to $33 \pm 9(p=0.01)$. MLHF markedly improved from $56(68-27)$ to $18(40-7)(p<0.01)$.

Conclusions: Our results support the safety and efficacy of the innovative Cardio-HKT rehabilitation program in patients with advanced $\mathrm{HF}$.

Keywords: hydrotherapy, aerobic training, skeletal muscle de-conditioning, dilated cardiomyopathy, cardiopulmonary exercise test, quality of life.

Monaldi Arch Chest Dis 2006; 66: 247-254.

Struttura Complessa di Cardiologia, A.O. Ospedale Santa Corona, Pietra Ligure (SV), Italy.

I Struttura Complessa di Pneumologia, A.O. Ospedale Santa Corona, Pietra Ligure (SV), Italy.

2 Unità Operativa di Cardiologia Clinica e Terapia dell' Insufficienza Cardiaca, Istituto Clinico Humanitas, Rozzano (MI), Italy.

3 Cardiologia 2 Trapianti, A.O. Ospedale Niguarda Ca' Granda, Milano, Italy.

Corresponding author: Annamaria Municinò, M.D.; Struttura Complessa di Cardiologia, A.O. Ospedale Santa Corona, Via XXV Aprile, 128 -17027 Pietra Ligure (SV), Italy; E-mail address: am072003@yahoo.it

\section{Introduction}

In patients (pts) with chronic heart failure (HF), physical training positively impacts on clinical outcome by improving aerobic capacity, autonomic tone, neuro-humoral abnormalities and skeletal muscle mitochondrial oxidative-enzyme activity [1-4].

With HF progression, worsening functional impairment may challenge pts ability to participate and adhere to conventional training programs. The lower peak aerobic capacity reached by advanced HF pts is mainly determined by skeletal muscle vasculature alterations that through reduced perfusion cause abnormalities in muscle metabolism and mass, further impairing functional capacity [5-11]. Frequent re-hospitalizations and recurrence of acute decompensation prolong periods of inactivity worsening HF pts functional status with additional negative impact on their ability to exercise, motivation and attitude. Exercise intolerance begets further progressive functional and self-confidence deterioration. A common finding in HF pts receiving cardiac rehabilitation treatment is psychosocial dysfunction; in particular depression has been shown to be an in- dependent risk factor for mortality and morbidity in patients with HF $[12,13]$. The drop out rate from cardiac exercise program is greatly influenced by patient motivation, training environment and selection of activities [14, 15].

Hydrotherapy, exercise in warm water, may be an attractive alternative to conventional training since its low-gravity, temperature controlled environment promotes muscle relaxation, peripheral thermal vasodilatation and assists joint movements; overall, it facilitates physical activity in patients with advanced functional impairment [16-18]. In-water immersion to the sternal notch has favourable cardiovascular, renal and neurohormonal effects in healthy subjects and in patients with HF [19-25]. Immersion increases thoracic blood volume, central venous pressure, and cardiac output; it decreases norepinephrine, epinephrine, renin, angiotensin II and aldosterone plasma levels; it promotes diuresis [26].

Hydrotherapy can be applied to patients with HF $[27,28]$, although its feasibility and safety remain controversial. In particular, concerns have been raised regarding the acute effects of immersion on central blood volume and systemic pressures [29-30]. 
Recent studies show that hydrotherapy is safe and beneficial on functional capacity in older patients with chronic HF of moderate degree [27, 28].

However, no study has investigated the effect of inwater training in patients with more advanced HF.

Previous trials have shown that pts adherence can be promoted by combining exercise with specific counseling (i.e. nutritional) with a decreased rates of subsequent cardiac events and hospitalization [31].

Accordingly, we studied patients with advanced HF on optimal medical treatment to evaluate the safety and efficacy of Cardio-Hydrokinesitherapy (Cardio-HKT), an innovative rehabilitation program performed in warm water and integrated by educational and psycho-behavioural support to promote healthy life style modification and long-term compliance.

\section{Methods}

\section{Population}

Patients with advanced HF followed by the HF services at the Istituto Clinico Humanitas and at the Niguarda Ca' Granda Hospital (Milano, Italy) were enrolled under the CARDIO-HKT Pilot Study. All patients gave written informed consent.

Entry criteria included the following: chronic $\mathrm{HF}$ of more than one year duration due to ischemic or non-ischemic dilated cardiomyopathy (DCM), left ventricular ejection fraction (LVEF) $\leq 35 \%$, NY$\mathrm{HA}$ functional class $\geq \mathrm{II}$, peak oxygen uptake (peak $\left.\dot{\mathrm{V}} \mathrm{O}_{2}\right) \leq 18 \mathrm{ml} / \mathrm{kg} / \mathrm{min}$, stable clinical conditions and optimal HF treatment for at least 3 months. Optimal HF treatment included the highest tolerated dosages of angiotensin-converting enzyme inhibitors (ACEI) or angiotensin receptors blockers (ARBs) and of beta-blockers, as well as any adjunctive electrical or surgical interventions indicated for HF (i.e. cardiac resynchronization therapy with biventricular pacing, implanted cardioverter defibrillator therapy, complete revascularization in case of ischemic DCM). Willingness to take part to an intensive exercise program and a written informed consent as approved by the local Ethics Committee was also required. Exclusion criteria were: recent (within 12 weeks) hemodynamic instability, chronic renal insufficiency (creatinine $>2.5 \mathrm{mg} / \mathrm{dL}$ ), presence of active infection or neoplastic disease.

\section{Facilities}

The Cardio - HKT Pilot Study was performed in an outpatient setting at a state-of-the-art rehabilitation facility located at Santa Corona Hospital (Pietra Ligure, Italy). The swimming pool, present in the Hospital facility, had $\mathrm{a} \sim 80 \mathrm{~m}^{3}$ capacity, with different depths (from $90 \mathrm{~cm}$ to $200 \mathrm{~cm}$ ), and special access ramps (internal and external). Seating and hydro-massage geyser spots helped muscle relaxation during the warm-up and recovery phases. Two separate "walking pools" or corridors with a rapid system to modify water depth and temperature were also available. Water temperature was maintained constant at $31 \cdot 0-32 \cdot 0^{\circ} \mathrm{C}$. Patient safety was ensured by a) a safe environment with emergency exit easily accessible from the swimming pool and related facilities; b) continuous supervision by a specialized team composed by one HF Cardiologist, one BLS/ACLS certified Cardiology Nurse, two Rehabilitation Therapists and one Nurse Aid; c) constant heart rate (HR) monitoring by wrist HR recorder; and d) standing emergency cart equipped with an automated external defibrillator. The hosting Institution provided patient accommodation in a guesthouse located nearby.

\section{The CARDIO-HKT training program}

The training program consisted in 2 in-water sessions per day, 5 days a week for a 3 -weeks period. Patients were divided into 4 groups of 4 to 5 pts each. Daily activities were scheduled from 9 AM to 5 PM, Monday to Friday and from 9 AM to 12 PM on Saturday (figure 1). Immersion time followed a stepwise progression from 30 to 50 minutes; each session consisted of 3 phases: a) warm up, b) training and c) recovery. Heart rate and modified Borg scale score were checked every two minutes during these phases. Oxygen saturation and blood pressure were monitored before and after exercise.

Patients then rested from physical activity for at least 4 hours. During these breaks, educational and psycho-behavioural support sessions were provided by the Cardiology Nurse and the HF Cardiologist to promote healthy life style changes and enhance adherence to the daily physical activity, weight control and low salt diet.

During the Cardio HKT program all pts followed a supervised low salt, "Mediterranean" type diet rich in polyunsaturated fatty acids.

Overall, the 3 weeks Cardio-HKT training program can be summarized in two phases: the "Adaptation Phase" and the "Tailored Training Phase" (figure 2).

In the 1 st week, the "Adaptation Phase" aimed to promote:

1. Adaptation to the water environment. Relaxing exercises with floating devices and whirlpool massage allowed patients to accustom to immersion and relax regarding their exercise performance.

2. Identification of low-workload exercises (Calisthenics), performed in immersion at the level of the sternal notch. These low-workload exercises, allowing to comfortably achieve the HR correspondent to $50 \%$ of peak oxygen uptake $\left(\dot{\mathrm{VO}}_{2}\right)$, facilitate peripheral muscles reconditioning.

3. Identification of preferential activities (i.e. swimming or in-water walking) at which each patient could reach and maintain the HR Target Range (HRTR $=$ HR at $60-70 \%$ of peak $\dot{\mathrm{VO}}_{2}$ or 10 beats below the HR at the anaerobic threshold).

In the $2^{\text {nd }}$ and $3^{\text {rd }}$ week, the "Tailored Training Phase" focused on:

1. Well-tolerated aerobic training within the HRTR for at least $20 \mathrm{~min}$. Different intensity and duration of exercise, and combination of lower and upper limb exercises were used to maintain HRTR for the entire training phase. 


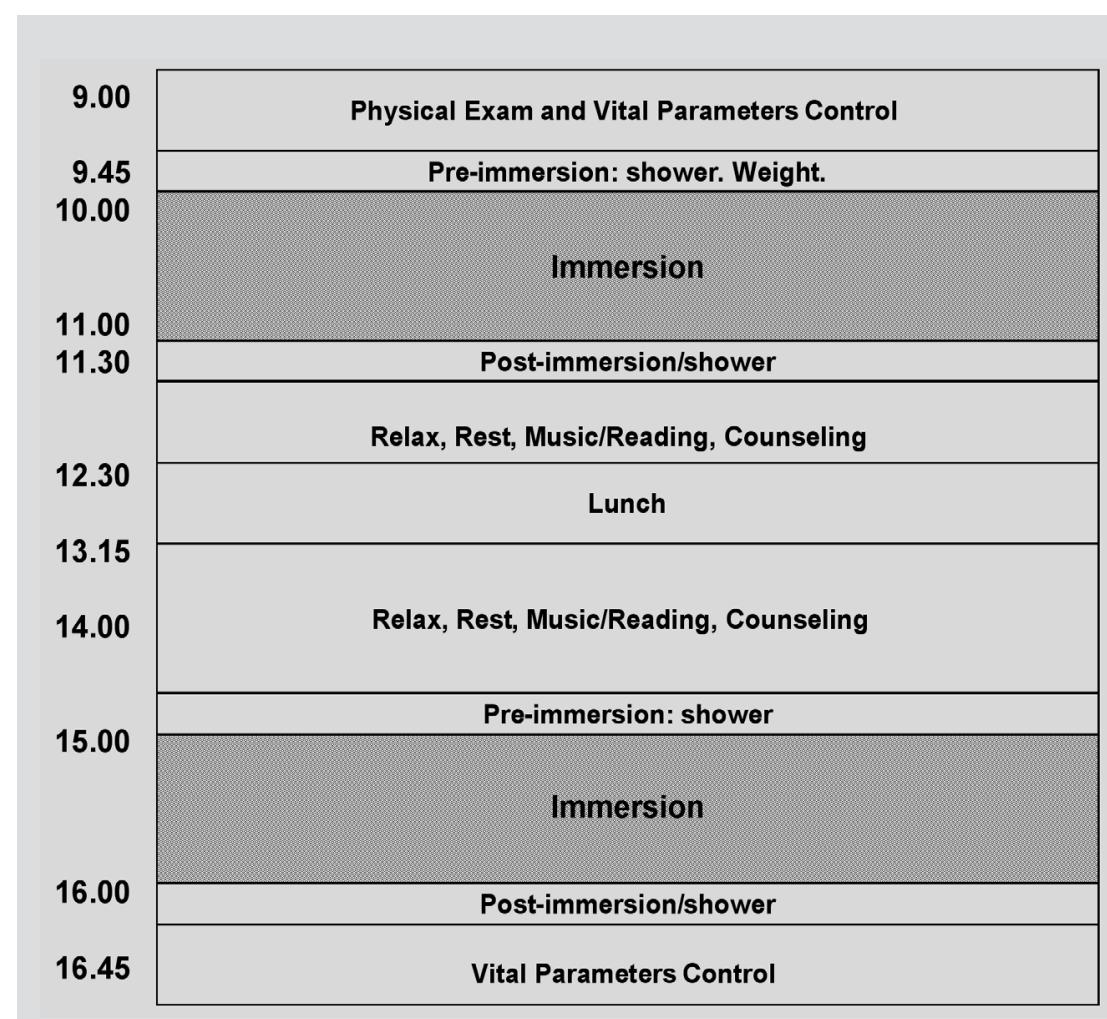

Figure 1. - The Cardio-HKT program daily schedule.

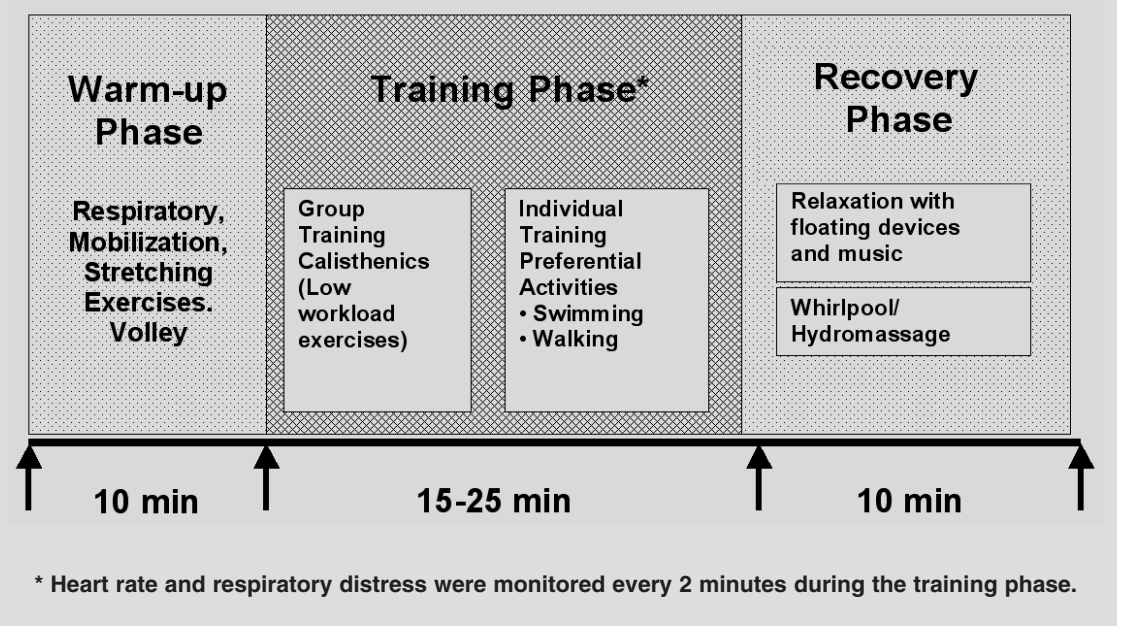

Figure 2. - Schematic showing how the immersion session was organized.

At the end of the Cardio-HKT program patients were instructed to continue the low salt diet and daily physical activity at home according to a dry land exercise protocol. A brochure showing the exercise sequence was provided to each patient. The HRTR derived from the final CPET was also indicated to reinforce home self-monitoring.

\section{Measurements}

Measurements were performed at baseline and after 3 weeks of Cardio-HKT. They included: a) patient interview and physical exam with estimation of NYHA functional class; b) body weight and body mass index (BMI), blood pressure and pulse oxygen saturation; c) routine blood testing for serum N-ter- minal pro B-type natriuretic peptide; d) 12 lead electrocardiogram; e) two-dimensional, Mmode and Doppler echocardiography; e) 6 minute walking test (6MWT), f) cardiopulmonary exercise testing (CPET), and g) quality of life assessment.

\section{NATRIURETIC PEPTIDE}

During the baseline evaluation session and at the end of the 3-weeks Cardio-HKT program patients underwent venesection for serum N-Terminal pro-Brain Natriuretic Peptide (NT proBNP) analyzed using Elecsys 2010 (Roche Diagnostic, Germany) [32].

\section{ECHOCARDIOGRAPHY}

M-mode and two-dimensional echocardiographic studies were performed at baseline and at the end of the 3-weeks Cardio-HKT program according to the recommendations of the American Society of Echocardiography [33] using a commercially available echocardiograph (Hewlett Packard, USA). Left ventricular end-diastolic volume (LV EDV) and end-systolic volume (LV ESV) were obtained from the apical 4- and 2- chamber views by a modified Simpson's rule, from which ejection fraction was automatically calculated as the difference between LV EDV and LV ESD normalized to LV EDV.

\section{SIX-MINUTE WALKING TEST (6MWT)}

Patients were asked to walk as far as possible during 6 minute while HR was monitored using a short-range radio telemetry (Sport-Tester, Polar Electro Oy, Kempele, Finland). Perceived exertion and rate of dyspnea was quantified using a modified Borg scale [34, 35]. All patients were familiar to the test as they performed it at least once in the past.

\section{Cardiopulmonary Exercise Testing (CPET)}

Patients biked on an electronically braked cycloergometer (Rehcor Lode) while wearing a nose clip and breathing through the mass flow sensor (dead space, $75 \mathrm{ml}$ ). ECG was continuously monitored. The Oxygen uptake $\left(\dot{\mathrm{V}}_{2}\right)$ and carbon dioxide output $\left(\dot{\mathrm{VO}}_{2}\right)$ were measured breath by breath through rapid gas analyzers (Vmax, SensorMedics, USA). After a 3-min resting measurement, the exercise 
load was increased by $10 \mathrm{~W}$ every min, maintaining the cycling rate from 50 to $60 \mathrm{rpm}$, until the imposed load could no longer be sustained. All patients were familiar with the test having performed it at least once as part of their previous HF evaluation. Ventilatory efficiency was assessed by calculating the slope of increasing minute ventilation (VE) versus $\mathrm{VCO}_{2}$. The $\mathrm{VE} / \mathrm{VCO}_{2}$ slope was measured by linear regression. The nonlinear part of the data after the onset of ventilatory compensation for metabolic acidosis was excluded [36].

\section{QuALITY OF LIFE AsSESSMENT}

Quality of life was assessed using the Minnesota Living with Heart Failure Questionnaire (MLHF) [37].

\section{Statistical Analysis}

Student's paired $t$-test was used to analyze differences between groups. Mann-Whitney U test was also used for non-parametric analysis. $\mathrm{P}<0.05$ was considered statistically significant. Functional data were expressed as mean $\pm S D$, unless otherwise indicated.

\section{Results}

Patient characteristics at baseline are summarized in table 1.

The Cardio-HKT program was well tolerated. All patients completed the program without complications. One patient did not qualify for CPET because unable to complete the test properly due to difficulties in breathing through the mass flow sensor. No adverse events were observed, including no shocks from implantable cardioverter-defibrillator and no symptomatic arrhythmias. Results are summarized in table 2. Increased physical activity and improved adherence to low-sodium diet likely explain the significant reduction in BMI. Resting HR, systolic and diastolic blood pressure before and after the training session did not change at the end of the three weeks program. Echocardiographic measurements of left ventricular dimensions and ejection fraction did not show any significant variation.

\section{Effect on Functional Capacity}

\section{SiX-MinUte Walking Test (6MWT)}

Walked distance increased from $453 \pm 172 \mathrm{~m}$ to $571 \pm 120$ meter $(p<0.01)$ after the 3 -weeks CardioHKT program. Borg scale did not change with a median value of 3.3 (4.9-2.6) before and 3.5 (4.8-2.6) $(\mathrm{p}=0.97)$ after the 3 -weeks Cardio-HKT program.

\section{Cardiopulmonary Exercise Testing (CPET)}

Peak $\mathrm{VO}_{2}$ increased from $13.0 \pm 3.1$ to $14.5 \pm 2.9$ $\mathrm{ml} / \mathrm{kg} / \mathrm{min}(\mathrm{p}=0.03)$ after the 3 -weeks Cardio-HKT program. Concurrently, VE/ $\mathrm{VCO}_{2}$ slope declined from $37 \pm 10$ to $33 \pm 9(\mathrm{p}<0.01) . \mathrm{VO}_{2}$ at the anaerobic threshold $\left(\mathrm{VO}_{2} @ \mathrm{AT}\right)$ and the respiratory exchange ratio did not show any statistically significant variation.

\section{Effect on Quality of Life}

The MLHF Total Score improved from a median value (upper-lower quartiles) of $56(68-27)$ to 18 $(40-7)(\mathrm{p}<0.01)$ after the 3 -weeks Cardio-HKT program.

\section{Effect on Neurohormonal Parameters}

After the 3 weeks training program NTproBNP levels were similar $(2299 \pm 1903$ vs $3283 \pm 4037 \mathrm{pg} / \mathrm{ml}$ $(\mathrm{p}=0.31)$, without any correlation with functional data.

\section{Discussion}

Our study shows that Cardio-HKT program is safe and effective in patients with advanced HF. We found that 3-weeks in-water training significantly improves functional capacity and quality of life in patients with advanced HF.

Our results are in agreement with recent reports showing that in-water exercise may positively affect functional capacity and quality of life of HF patients $[27,28]$. However, these studies enrolled older patients with chronic HF of milder degree (as defined by a functional class NYHA not greater than III and by left ventricular mean ejection fraction $\geq 32 \%$ ). Our findings broaden the applications of hydrotherapy programs to patients with more advanced cardiac and functional impairment.

The present Pilot Study addresses concerns raised by other investigators $[29,30]$ regarding safety of in-water exercise in patients with HF: CardioHKT program was safe and very well tolerated. Continuous supervision, patient reassurance and frequent monitoring of vital signs during exercise likely contributed to minimize the incidence of adverse events.

\section{Effect on Functional Parameters}

In advanced heart failure, physical inactivity promotes de-conditioning, a widespread phenomenon involving not only respiratory and skeletal muscles but also the entire peripheral circulation. Since exercise intolerance in HF is a consequence of both skeletal muscle and cardiovascular dysfunction, improving peripheral muscle function in these pts represents a target as important as reversing the cardiovascular alterations [6-8]. The lower peak aerobic capacity reached by advanced HF pts is mainly determined by skeletal muscle vasculature alterations that through reduced perfusion cause abnormalities in muscle metabolism and mass, further impairing their functional capacity [1-5]. Patients may avoid walking and climbing stairs as HF progresses, and these behavioural changes result in more pronounced muscular alterations of the lower limbs when compared to the upper limbs [38].

In-water exercise may ease reconditioning particularly of the lower limbs muscles, since low-gravity facilitates physical activity by minimizing effort thereby assisting movements and allowing effective aerobic training needed to favor recovery of vascular abnormalities. Thermal-induced vasodilatation 


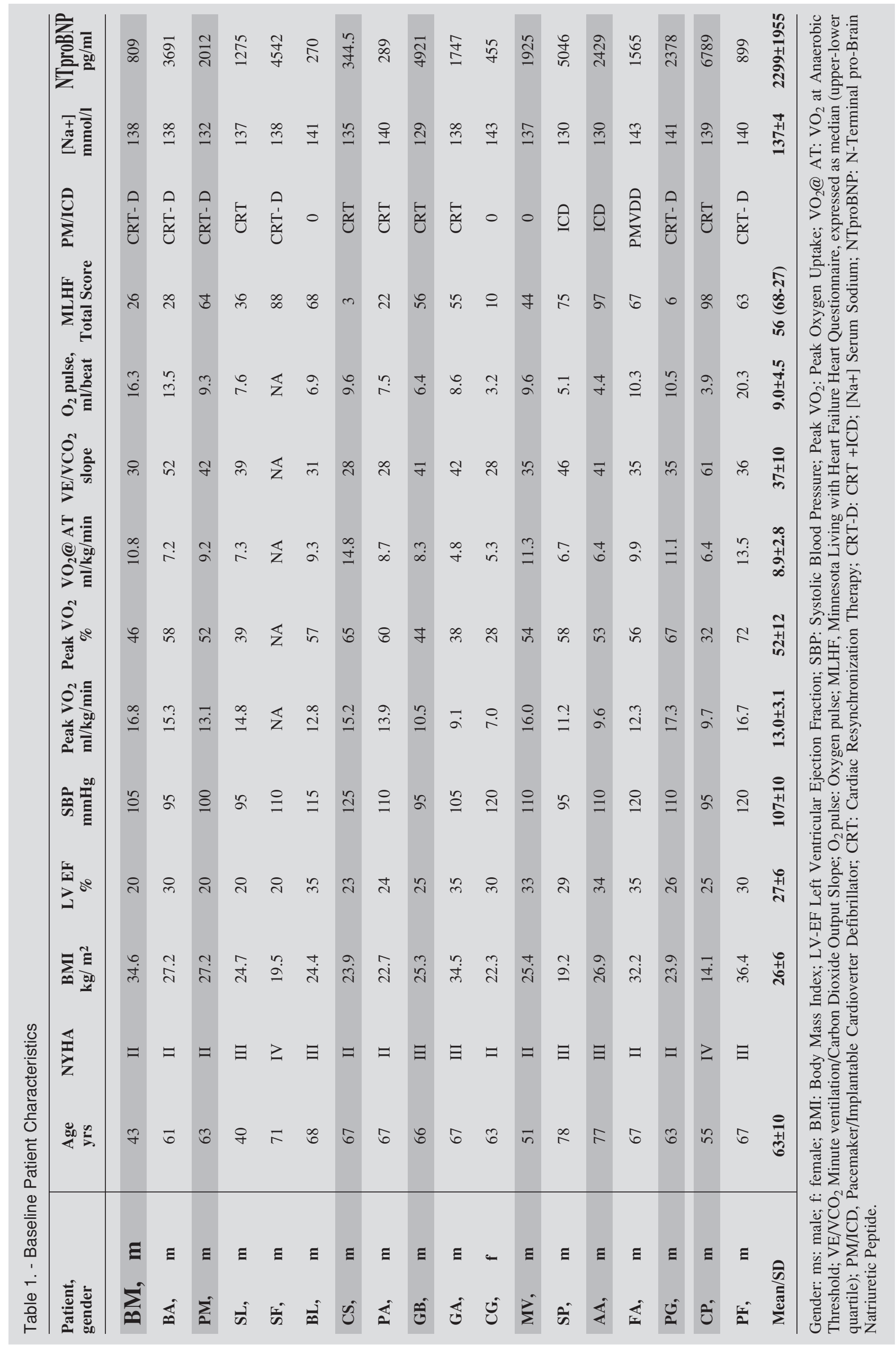


Table 2. - Differences in measurements from baseline to 3 weeks. Effect of CardioHKT program on clinical, functional, neuro-hormonal parameters and quality of life

\begin{tabular}{|c|c|c|c|}
\hline & Baseline & Final & p-value \\
\hline Body Weight (kg) & $79.5 \pm 23.7$ & $78.4 \pm 23.2$ & 0.06 \\
\hline BMI $\left(\mathrm{kg} / \mathrm{m}^{2}\right)$ & $26.1 \pm 5.9$ & $25.7 \pm 5.6$ & $* *<0.01$ \\
\hline LVEF (\%) & $27.0 \pm 6.0$ & $26.7 \pm 6.5$ & NS \\
\hline 6mWT (m) & $453 \pm 172$ & $571 \pm 120$ & $* *<0.01$ \\
\hline$\dot{\mathrm{V}} \mathrm{O}_{2}(\mathrm{ml} / \mathrm{min})$ & $1057 \pm 422$ & $1153 \pm 391$ & $* 0.04$ \\
\hline$\dot{\mathrm{V}} \mathrm{O}_{2} /$ weight $(\mathrm{ml} / \mathrm{kg} / \mathrm{min})$ & $13.0 \pm 3.1$ & $14.5 \pm 2.9$ & $* 0.03$ \\
\hline$\dot{\mathbf{V}} \mathrm{O}_{2} @ \mathrm{AT}$ (ml/kg/min) & $8.9 \pm 2.3$ & $9.0 \pm 2.1$ & NS \\
\hline $\mathrm{VE} / \mathrm{VCO}_{2}$ slope & $37 \pm 10$ & $33 \pm 9$ & $* *<0.01$ \\
\hline $\mathrm{O}_{2}$ pulse (ml/beat) & $9 \pm 4$ & $9 \pm 4$ & NS \\
\hline Work load $(W)$ & $86.2 \pm 29.1$ & $93.1 \pm 30.0$ & NS \\
\hline MLHF (median T-score) & $56(68-27)$ & $18(40-7)$ & $* *<0.01$ \\
\hline NT proBNP (pg/ml) & $2299 \pm 1903$ & $3283 \pm 4037$ & NS \\
\hline Serum Sodium $(\mathrm{mmol} / \mathrm{L})$ & $137 \pm 4$ & $136 \pm 4$ & NS \\
\hline
\end{tabular}

Data are shown as mean values $( \pm \mathrm{SD})$ or median.

Statistical significance: $*=p<0.05, * *=p<0.01, * * *=p<0.001$ versus baseline values.

Baseline and Final refer to measures obtained prior and after the 3-weeks Cardio-HKT program.
HF diagnosis and its prognostic stratification $[40,41]$. They have been associated to impaired left ventricular systolic function and reduced exercise capacity in pts with HF [42-44]. In our study we did not found differences in NT-proBNT levels before and after treatment and no correlation with functional data.

Further studies are needed, involving a larger advanced HF pts group with a more homogenous pharmacological treatment since neurohormonal drugs, as ACE-I, ARBs and diuretics may affect circulating level of cardiac natriuretic peptides. and hydro-massage promote muscular and psychological relaxation and exercise training beneficially affects systemic inflammation and neuro-hormonal activation observed in advanced HF stage [39], thereby reinforcing the action of the standard pharmacotherapy.

In Cardio-HKT participants, the improvements in 6MWT were more impressing than those observed during CPET, implying that motivation might have played an important role in improving pts performance. Immersions in a low-gravity environment may not only facilitate re-conditioning prior to aerobic training, but also promote patient relaxation and sense of well being that in turn may have fostered their motivation.

We are aware that a 3 -weeks training period may be not long enough to achieve a durable result or to determine any significant left ventricular reverse remodeling (i.e. detectable by echocardiography); in the meanwhile we have to acknowledge its positive impact on pts motivation through a significant well being improvement.

\section{Effect on Quality of Life}

We found that the most beneficial effect of our Cardio-HKT program was the improvement in QOL. Supervised in-water exercise facilitates reconditioning and it may be more effective than conventional training in promoting patient reassurance and relaxation.

Quality of life rather than survival per se should be considered as a more desirable and realistic longterm target in optimally treated patients with advanced $\mathrm{HF}$.

\section{Effect on Neurohormonal Parameters}

Natriuretic peptides (B-type natriuretic peptide and NT-proBNP) plasma levels increase in response to cardiac wall stretch, volume expansion and neurohormonal activation and have a growing role in

\section{Conclusions}

In conclusion, our findings demonstrate that the innovative, continuously supervised in-water Cardio-HKT program is safe and significantly improves functional capacity and quality of life in patients with advanced HF. The present Cardio-HKT Pilot Study also shows that peripheral rather than cardiac effects may be responsible for these improvements.

Future randomized trials will address whether in-water Cardio-HKT program is superior to conventional exercise programs in patients with advanced $\mathrm{HF}$.

\section{Riassunto}

Lo studio pilota Cardio-HKT, Cardio-Idrokinesiterapia, si propone di dimostrare $i$ vantaggi di un innovativo protocollo di esercizi riabilitativi aerobici condotti in acqua riscaldata a $31^{\circ} \mathrm{C}$ nell' ambito di un programma integrato da supporto psicocomportamentale e sessioni educazionali per il miglioramento dello stile di vita di pazienti con insufficienza cardica avanzata (ICA).

Metodi: $18 \mathrm{pz}$ con ICA stabile in terapia ottimizzata, classe funzionale NYHA <II, frazione d'eiezione $27 \pm 7 \%$, consumo di ossigeno di picco $\left(\mathrm{pVO}_{2}\right)<18 \mathrm{ml} / \mathrm{kg} / \mathrm{m}$, hanno partecipato all' innovativo programma pilota Cardio-HKT per 3 settimane in 2 sessioni quotidiane di training personalizzato ad intensità progressiva e con supervisione continua. La frequenza cardiaca allenante (FCA) corrispondente al $60-70 \%$ della $\mathrm{pVO}_{2}$ rappresentava il target da raggiungere e mantenere per garantire lo svolgimento di un'attività aerobica sottomassimale.

Risultati: Tutti i pz sono stati in grado di portare a termine gli esercizi programmati senza complicanze. La valutazione funzionale ha mostrato un miglioramento del six minutes walking test da $453 \pm 172 \mathrm{~m}$ a 571 $\pm 120 \mathrm{~m}(\mathrm{p}<0.01)$, e del $p V O_{2} \mathrm{da}$ $13.0 \pm 3.1$ a $14.5 \pm 2.9 \mathrm{ml} / \mathrm{kg} / \mathrm{min}(p=0.03)$. Inoltre il punteggio finale del questionario sulla qualità di vi- 
ta, Minnesota Living with Heart Failure Questionnaire, è migliorato da 56 (68-27) a 18 (40-7) $(p<0.01)$.

Conclusioni: Per la prima volta in pazienti con ICA un esperienza di attività fisica in acqua a temperatura controllata si è dimostrata fattibile, priva di eventi avversi ed in grado di migliorare la capacità funzionale e la qualità di vita.

Parole chiave: idroterapia, training aerobico, decondizionamento muscolare periferico, cardiomiopatia dilatativa, test cardiopolmonare, qualità di vita.

Acknowledgements: We are grateful to all the members of the Cardio-HKT team (Michele Rebella, Flavio Oddone, Alessandro Robutti, Agostino De Stefani, Maria Grazia Ottonello, Antonio Ferro e Maria Laura Ferrero) that with their enthusiasm and dedication made this study possible. We also thank the S. Corona Hospital Administrative Services for extraordinary cooperation and involvement in hosting the Cardio-HKT Pilot Study.

\section{ABBREVIATIONS/ACRONYMS LIST}

HF $\quad=$ Heart Failure

Cardio-HKT $=$ Cardio-Hydrokinesitherapy

LVEF = Left Ventricular Ejection Fraction

ACEI = Angiotensin-Converting Enzyme Inhibitors

ARBs = Angiotensin Receptors Blockers

BMI $=$ Body Mass Index

NT proBNP $=$ N-Terminal pro B-type Natriuretic Peptide

$6 \mathrm{MWT}=6$ Minute Walking Test

CPET = Cardiopulmonary Exercise Testing

QOL = Quality of Life

LV EDV = Left Ventricular End-Diastolic Volume

LV ESV = Left Ventricular End-Systolic Volume

HR = Heart Rate

$\mathrm{p} \dot{\mathrm{V}}_{2} \quad=$ Peak Oxygen Uptake

$\dot{\mathrm{V}}_{2} \quad=$ Oxygen uptake

$\dot{\mathrm{V} C O}_{2}=$ Carbon dioxide output

$\mathrm{VE} \quad=$ Minute Ventilation

MLHF = Minnesota Living with Heart Failure Questionnaire

\section{References}

1. Sullivan MJ, Higginbotham MB, Cobb FR. Exercise training in patients with severe left ventricular dysfunction: hemodynamic and metabolic effects. Circulation 1988; 78: 506-515.

2. Coats AJS, Adamopoulos S, Radaelli A, McCAnce A, Meyer TE, Bernardi L, et al. Controlled trial of physical training in chronic heart failure: exercise performance, hemodynamics, ventilation, and autonomic function. Circulation 1992; 85: 2119-2131.

3. Belardinelli R, Georgiu D, Cianci G, Purcaro A. Randomized, controlled trial of long term moderate exercise training in chronic heart failure: effects on functional capacity, quality of life and clinical outcome. Circulation 1999; 99 (9): 1173-82.

4. Piepoli MF, Davos C, Francis DP, Coats AJ ExTraMATCH Collaborative. Exercise training meta-analysis of trials in patients with chronic heart failure (ExTraMATCH). BMJ 2004; 328 (7433): 189.

5. Wilson JR, Martin JL, Schwartz D, Ferraro N. Exercise intolerance in patients with chronic heart failure: role of impaired nutritive flow to skeletal muscle. Circulation 1984; 69 (6): 1079-87.

6. Mancini DM, Walter G, Reichek N, Lenkinski R, McCully KK, Mullen JL, Wilson JR. Contribution of skeletal muscle atrophy to exercise intolerance and altered muscle metabolism in heart failure. Circulation 1992; 85: 1364-1373.

7. Wilson JR, Mancini DM. Factors contributing to the exercise limitation of heart failure. J Am Coll Cardiol 1993; 22 (4 Suppl A): 93A-98A.

8. Wilson JR, Mancini DM, Dunkman WB. Exertional fatigue due to skeletal muscle dysfunction in patients with heart failure. Circulation 1993; 87 (2): 470-5

9. Hambrecht R, Niebauer J, Fiehn E, Kalberer B, Offner B, Hauer K, et al. Physical training in patients with stable chronic heart failure: effects on cardiorespiratory fitness and ultrastructural abnormalities of leg muscles. $J \mathrm{Am}$ Coll Cardiol 1995; 25: 1239-49.

10. Sullivan MJ, Hawthorne MH. Exercise intolerance in patients with chronic heart failure. Prog Cardiovasc Dis 1995; 38: 1-12.

11. Le Jemtel TH, Low M, Mancini D. Physical training should be targeted to the periphery in patients with chronic heart failure. Heart Fail 1997; 13 (2): 92-95.

12. Rozanski A, Blumenthal JA, Kaplan J. Impact of psychological factors on the pathogenesis of cardiovascular disease and implications for therapy. Circulation 1999; 99: 2192-2217.

13. Jiang W, Kuchibhatla M, Cuffe MS, Christopher EJ, Alexander JD, Clary GL, et al. Prognostic value of anxiety and depression in patients with chronic heart failure. Circulation 2004; 110: 3452-3456.

14. Oldridge NB. Compliance and dropout in cardiac exercise rehabilitation. J Cardiac Rehabil 1984; 4: 166-77.

15. Ades PA. Cardiac rehabilitation and secondary prevention of coronary heart disease. $N$ Engl J Med 345; 12 : 892-902.

16. Hall J, Skevington SM, Maddison PJ, Chapman K. A randomized and controlled trial of hydrotherapy in rheumatoid arthritis. Arthritis Care Res 1996; 9 (3): 206-15.

17. Hall JBD, O'Hare P. The physiology of immersion. Physiotherapy 1990; 76 (9): 517-521.

18. Sramek P, Simeckova M, Janski L, Savlikova J, Vybiral S. Human Physiological responses to immersion into water of different temperatures. Eur J Appl Physiol 2000; 81 (5): 436-442.

19. Gabrielsen A, Sorensen VB, Pump B, Galatius S, Videbaek $\mathrm{R}$, Bie $\mathrm{P}$, et al. Cardiovascular and neuroendocrine responses to water immersion in compensated heart failure. $\mathrm{Am}$ J Physiol Heart Circ Physiol 2000; 279; H1931-H1940.

20. Perini R, Milesi S, Biancardi L, Pendergast DR, Veicsteinas A. Heart rate variability in exercising humans: effect of water immersion. Eur J Appl Physiol 1998; 77 (4); 326-32.

21. Sheldahl LM, Tristani FE, Clifford PS, Kalbfleish JH, Smits G, Hughes CV. Effect of head out immersion on response to exercise training. J Appl Phisiol 1986; 60: $1878-81$

22. Kinney EL, Cortada X, Ventura R. Cardiac size and motion during water immersion: implications for volume homeostasis. Am Heart J 1987 Feb; 113 (2 Pt 1): 345-9.

23. Smith DE, Kaye AD, Mubarek SK, Kusnick BA, Anwar M, Friedman IM, Nossaman BD. Cardiac Effects of Water Immersion in Healthy Volunteers. Echocardiography 1998 Jan; 15 (1): 35-42.

24. Gabrielsen A, Johansen L, Norsk P. Central cardiovascular pressures during graded water immersion in humans. $J$ Appl Physiol 1993; 75: 581-585.

25. Tei C, Horikiri Y, Park JC, Jeong JW, Chang KS, Toyama $\mathrm{Y}$, et al. Acute hemodynamic improvement by thermal vasodilatation in congestive heart failure. Circ 1995 15; 91 (10): 2582-90.

26. Epstein M. Renal effects of head out immersion in humans: a 15-year update. Physiol Rev 1992; 72: 563-621.

27. Cider A, Schaufelberger M, Stibrant Sunnerhagen K. Hydrotherapy - a new approach to improve function in the older patient with chronic heart failure. Eur J H Fail 2003; 5: 527-535. 
28. Cider A, Svealy BG, Tang MS, Schaufelberger M, Andersson B. Immersion in warm water induces improvement in cardiac function in patients with chronic heart failure. Eur J Heart Fail 2006; 8: 308-313.

29. Meyer K. Exercise training in heart failure: recommendations based on current research. Med Sci Sports Exerc 2001; 33: 525-531.

30. Meyer K, Bucking J. Exercise in heart failure: should aqua therapy and swimming be allowed? Med Sci Sports Exerc 2004; 36 (12): 2017-23.

31. Ornish D, Scherwitz LW, Billings $\mathrm{JH}$, et al. Intensive lifestyle changes for reversal of coronary heart disease. JAMA 1998; 280: 2001-7.

32. Sokoll LJ, Baum H, Collinson PO, et al. Multicenter analytical performance evaluation of the Elecsys proBNP assay. Clin Chem Lab Med 2004; 42: 965-72.

33. Schiller NB, Shah PM, Crawford M, DeMaria A, Devereux R, Feigenbaum $\mathrm{H}$, et al. Recommendations for quantitation of the left ventricle by two dimensional echocardiography. J Am Soc Echocardiogr 1989; 2: 358267.

34. Lipkin D, Crake T, Poole-Wilson PA. Six minute walking test for assessing exercise capacity in chronic heart failure patients. BMJ 1986; 292: 653-655.

35. Borg G. Ratings of perceived exertion and heart rates during short term cycle exercise and their use in a new cycling strength test. Int Sports Med 1982; 3 (3): 153-8.

36. American Thoracic Society/American College of Chest Physician. ATS/ACCP statement on cardiopulmonary exercise testing. Am J Respir Crit Care Med 2003: 167: 211-277.
37. Rector TS, Cohn JN. Assessment of patient outcome with the Minnesota Living with Heart Failure questionnaire: reliability and validity during randomized, double-blind, placebo controlled trial of pimobendan. Pimobendan Multicenter Research group. Am Heart J 1992; 124 (4): 1017-25.

38. Jondeau G, Katz SD, Toussaint J-F, et al. Regional specific of peak hyperemic response in pts with congestive heart failure: correlation with peak aerobic capacity. $J \mathrm{Am}$ Coll Cardiol 1993; 22: 1399-1402.

39. Peterson AMW, Pendersen BK. The anti-inflammatory effect of exercise. J Appl Physiol 2005; 98 (4): 11541162.

40. Schrier R, Abraham W. Hormones and hemodynamics in heart failure. $N$ Engl J Med 1999; 341: 577-85.

41. Levin ER, Gardner DG, Samson WK. Natriuretic Peptides. N Engl J Med 1998; 339: 321-8.

42. Williams SG, Ng LL, O'Brein RJ, Taylor S, et al. Comparison of plasma N-brain natriuretic peptide, peak oxygen consumption, and left ventricular ejection fraction for severity of chronic heart failure. Am J Cardiol 2004; 93: 1560-1.

43. Kruger S, Graf J, Kunz D, Stickel T, Hanrath P, Janssens $\mathrm{U}$. Brain natriuretic peptide levels predict functional capacity in patients with chronic heart failure. $J$ Am Coll Cardiol 2002; 40: 718-22.

44. de Groote P, Dagorn J, Soudan B, Lamblin N, McFadden E, Bauters C. B-type natriuretic peptide and peak oxygen consumption provide independent information for risk stratification in patients with stable congestive heart failure. J Am Coll Cardiol 2004; 43: 1584-9. 